Neuroepidemiology 2017;49:31-33

DOI: $10.1159 / 000479698$

\section{Dose-Response Relationship between the Risk of Vasovagal Syncope and Body Mass Index or Systolic Blood Pressure in Young Adults Undergoing Blood Tests}

Tomohide Yamada ${ }^{\mathrm{a}, \mathrm{b}}$, Shintaro Yanagimoto ${ }^{\mathrm{b}}$

${ }^{a}$ Department of Diabetes and Metabolic Diseases, Graduate School of Medicine, and bivision for Health Service Promotion, The University of Tokyo, Tokyo, Japan

Vasovagal syncope (VVS) is the most common type of syncope [1]. VVS usually resolves uneventfully, but sometimes leads to head trauma or other injuries [1]. The impact of syncope on public safety (e.g., syncope while driving) has also attracted recent interest $[2,3]$. Blood tests are the most commonly performed medical tests, and prevention of VVS associated with blood sample collection is important.

We investigated the association between body mass index (BMI), systolic blood pressure (SBP), and the risk of VVS in healthy young adults undergoing blood tests, and attempted to quantify potential dose-response relation.

We examined 18,888 students (19\% women) entering the University of Tokyo between 2011 and 2016, who had a normal electrocardiogram, and no previous syncopal loss of consciousness. A blood sample $(10 \mathrm{~mL})$ was collected for health screening along with measurement of BMI and blood pressure. VVS was defined as syncope occurring before, during, or immediately after the collection of blood sample, with symptoms such as weakness, pallor, nausea, reduction of the SBP or pulse rate compared with baseline, and/or need for assistance from a physician, all without any sequelae. Multiple logistic regression analysis was employed to determine the adjusted OR and 95\% CI for associations between the risk of VVS and BMI or SBP. For evaluation of potential nonlinear relationships, we applied cubic splines with 4 knots in set percentiles of the distribution $(5,35,65$, and $95 \%)$ to model possible associations.

VVS was diagnosed in $0.63 \%$ of the subjects $(n=119 ; 0.61 \%$ of men and $0.65 \%$ of women, $p=0.85$ ). Underweight physique (BMI $\left.<18.5 \mathrm{~kg} / \mathrm{m}^{2}\right), \mathrm{SBP}<90 \mathrm{~mm} \mathrm{Hg}$, and SBP $<100 \mathrm{~mm} \mathrm{Hg}$ were noted in $19,0.7$, and $7.2 \%$ of the VVS group, respectively.

By dose-response analysis, lower BMI showed a non-linear association with a significantly higher risk of VVS ( $p$ for nonlinearity $<0.001$; Fig. 1a) after adjustment for age and SBP. Compared with a BMI of $22 \mathrm{~kg} / \mathrm{m}^{2}$, the risk of VVS increased markedly at a BMI of $18.5 \mathrm{~kg} / \mathrm{m}^{2}(2.22,1.36-3.62)$. Similarly, com- pared with the median SBP $(120 \mathrm{~mm} \mathrm{Hg})$, lower SBP showed a linear association with a higher risk of VVS (90 mm Hg: 3.18, $1.55-6.54 ; p$ for non-linearity $=0.09$; Fig. $1 \mathrm{~b}$ ) after adjustment for age and BMI. There were no significant differences of other baseline characteristics between the VVS and non-VVS groups (hemoglobin: $15.2 \pm 1.1$ vs. $14.9 \pm 1.3 \mathrm{~g} / \mathrm{dL}, p=0.1$; age: $18.4 \pm 0.8$ vs. $18.5 \pm 1.3$ years, $p=0.72$; time from last meal to blood test: $7.6 \pm$ 2.8 vs. $7.9 \pm 2.8 \mathrm{~h}, p=0.46$; and creatinine: $0.79 \pm 0.13$ vs. $0.78 \pm$ $0.13 \mathrm{mg} / \mathrm{dL}, p=0.85$ ).

Analysis stratified by gender showed similar results in males, but not in females. In males, VVS risk increased at a BMI of 18.5 $\mathrm{kg} / \mathrm{m}^{2}(2.35,1.41-3.92)$ and SBP of $90 \mathrm{~mm} \mathrm{Hg}(4.41,1.91-10.2)$, but there was no significant relation between VVS and BMI or SBP in females. The gender difference was possibly due to the relatively small female population (females $n=3,522$, males $n=15,366$ ), leading to insufficient statistical power.

VVS occurs because autonomic "hypersensitivity" to triggering stimuli (dehydration, pain, and stress) results in simultaneous enhancement of parasympathetic tone and suppression of sympathetic tone that slows the heart rate and reduces the blood pressure, leading to cerebral ischemia and syncope [1]. In contrast to blood donation, only $10 \mathrm{~mL}$ of blood is collected for health screening. One possibility is that persons with low SBP and low BMI might show an impaired muscle contractile response to a sharp decline of blood pressure. Limitations of this study include its single-center design and no information about psychological factors related to VVS [1].

Although unknown confounders may have influenced the results, we demonstrated a dose-response relation between VVS and $\mathrm{BMI}$ or SBP. Lower BMI and SBP were positively associated with the occurrence of VVS. Advice on preventive methods such as the counter-pressure maneuver [4] and water ingestion [5] might be beneficial for high-risk persons, especially those who are "underweight" or have "hypotension".

\section{Acknowledgments}

None.

\section{Disclosure Statement}

No potential conflicts of interest relevant to this article were reported.

\section{Funding}

The authors have no funding.

\section{KARGER}

() 2017 S. Karger AG, Basel

E-Mail karger@karger.com

www.karger.com/ned
Tomohide Yamada, MD

Department of Diabetes and Metabolic Diseases Graduate School of Medicine

7-3-1 Hongo, Bunkyo, Tokyo 113-8655 (Japan)

E-Mail bqx07367@yahoo.co.jp 


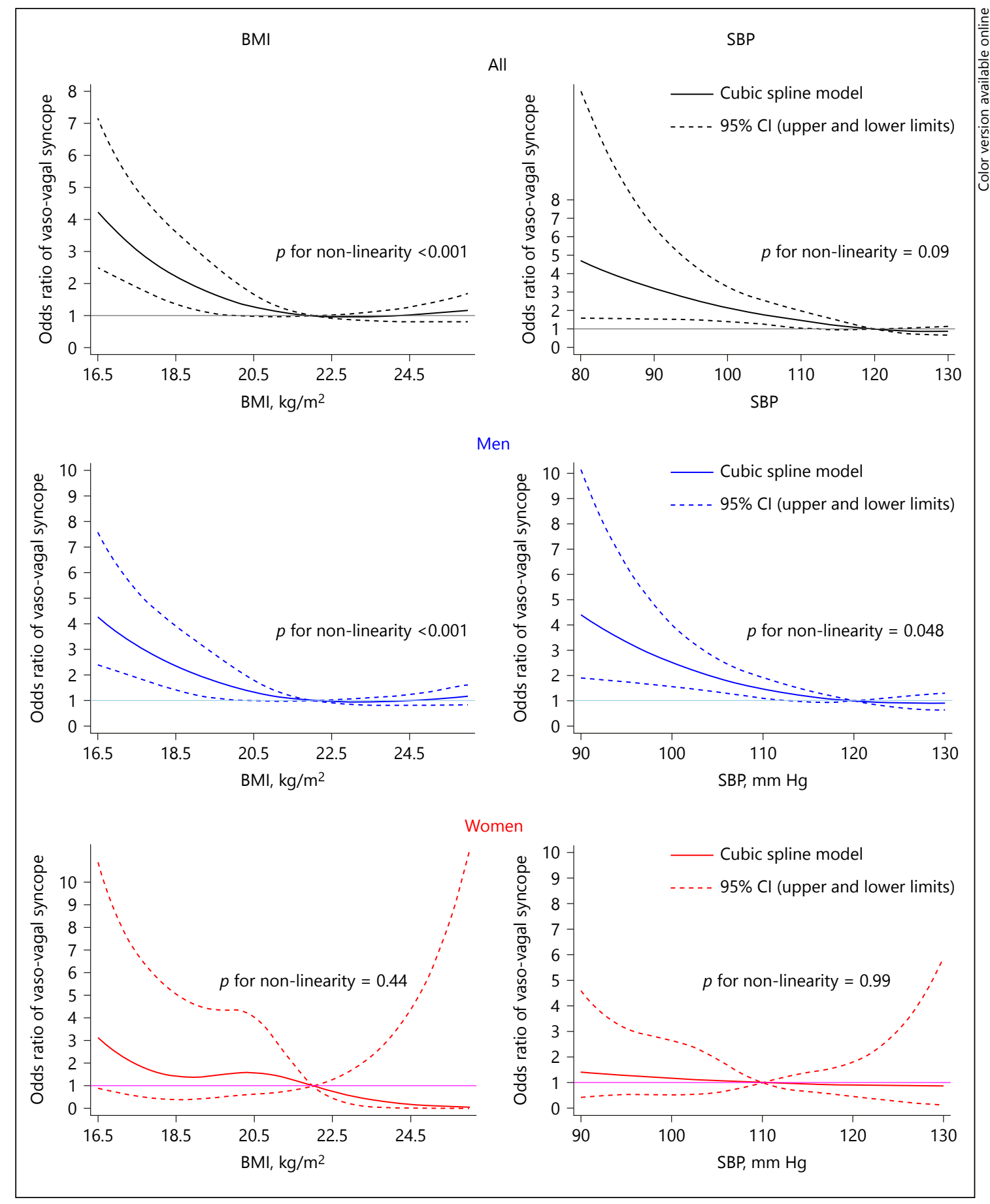

Fig. 1. Dose-response relationship between the risk of vasovagal syncope and (a) body mass index or (b) systolic blood pressure in healthy young adults undergoing blood tests. (1) Analysis adjusted for age and systolic pressure. The reference value was $22.0 \mathrm{~kg} / \mathrm{m}^{2}$. (2) Analysis adjusted for age and body mass index. The reference value was $120 \mathrm{~mm} \mathrm{Hg}$ (median) for men and $110 \mathrm{~mm} \mathrm{Hg}$ (median) for women. For evaluation of potential non-linear relationships, we applied cubic splines with 4 knots in set percentiles of the distribution $(5,35,65$, and $95 \%)$ to model possible associations. 


\section{References}

1 Tan MP, Parry SW: Vasovagal syncope in the older patient. J Am Coll Cardiol 2008;51:599-606.

2 Curtis AB, Epstein AE: Syncope while driving: how safe is safe? Circulation 2009;120:921-923.

3 Sorajja D, Nesbitt GC, Hodge DO, Low PA, Hammill SC, Gersh BJ, Shen WK: Syncope while driving: clinical characteristics, causes, and prognosis. Circulation 2009;120:928-934.
4 Krediet CT, van Dijk N, Linzer M, van Lieshout JJ, Wieling W: Management of vasovagal syncope: controlling or aborting faints by leg crossing and muscle tensing. Circulation 2002;106:1684-1689.

5 Lu CC, Diedrich A, Tung CS, Paranjape SY, Harris PA, Byrne DW, Jordan J, Robertson D: Water ingestion as prophylaxis against syncope. Circulation 2003;108:2660-2665. 